\title{
The Effects of Exergames on the Attitudes of Secondary School Female Students towards Physical Education
}

\author{
Yakup Zühtü Birinci (Corresponding author) \\ Faculty of Sport Sciences, Bursa Uludağ University, Bursa, Turkey \\ E-mail: ykpbirinci@gmail.com

\begin{abstract}
Nimet Haş11 Korkmaz
Faculty of Sport Sciences, Bursa Uludağ University, Bursa, Turkey

E-mail: nhasil@uludag.edu.tr
\end{abstract}

Murat Deniz

Uludağ Religious Vocational High School, Bursa, Turkey

E-mail: muratdeniz81@hotmail.com

Serkan Pancar

Faculty of Sport Sciences, Aksaray University, Aksaray, Turkey

E-mail: sdpancar@gmail.com

Gökhan Çetinoğlu

Faculty of Sport Sciences, Bursa Uludağ University, Bursa, Turkey

E-mail: gokhan.cetinoglu@hotmail.com

Hüseyin Topçu

Faculty of Sport Sciences, Bursa Uludağ University, Bursa, Turkey

E-mail: h.topcu88@gmail.com 
Received: November 5, $2021 \quad$ Accepted: November 27, 2021

Published: December 31, 2021

doi:10.5296/jei.v7i3.19187

URL: https://doi.org/10.5296/jei.v7i3.19187

\begin{abstract}
Growing studies show that exergames (EG) which can combine physical activity (PA) and games is an effective educational tool in physical education (PE). The purpose of this research was to evaluate the effect of dance-based EG on the attitude of 8th grade female students towards PE.
\end{abstract}

The research group consists of 15 female students who are educated in the 8th grade of secondary education in the public school of Bursa province. Participants performed dance-based EG for 80 minutes (3 sets of 20 minutes sessions, 10 minutes rest between sessions), 3 days a week for 8 weeks. Music and dance content were changed after each 20-minute game. Participants answered the Physical Education and Sports Attitude Scale (PESAS) before the first exergame session and at the end of 8 weeks.

Shapiro-Wilk and Kolmogorov-Smirnov tests were used to determine whether the variables are normally distributed. Mann-Whitney $U$ test was used for pairwise comparisons, Kruskal-Wallis Analysis of Variance was used for multiple comparisons. The relationships between the variables were examined with the Spearman-correlation coefficient.

A statistically significant difference was found between the participants' PESAS pre-test and post-test scores $(p=0.001)$. Based on the results of the study it can be concluded that dance-based EG is useful for developing positive attitudes towards PE among female students.

Keywords: Active video game, Attitude, Exergame, Female student, Physical education

\title{
1. Introduction
}

Schools are highly critical learning environments to develop child health and wellbeing via physical education (PE). One of the most important outcomes of this course is to instill knowledge and consciousness of physical activity (PA). Ensuring that children include PA in their lives continuously and correctly is one of the most effective weapons to deal with obesity, which is the most important and ever-increasing public health problem affecting the whole world today. But physical education (PE) teachers have to struggle with many problems in order to increase PA levels by changing the attitude of students.

Today with the rapid development of technology, children prefer sedentary activities such as using the phone, playing video games and watching television rather than physical activities such as running, rolling, turning, jumping and climbing (Korkmaz et al., 2020). PA and exercise are not interesting and perceived as difficult and tiring make it difficult for children to take action. If children can perceive PA as fun and enjoyable, they will tend to participate more in PA (Fogel et al., 2010; Jekauc, 2015; Schneider \& Kwan, 2013). 
Particularly, some negative experiences of female students in the transition phase from childhood to adolescence in PE class cause them to have negative attitudes towards PE (Cairney et al., 2012). This situation is thought to be one of the important reasons why the level of participation in PA of girls decreased more than boys. Treanor et al. (1998) demonstrated lower levels of PE class enjoyment among girls than boys. Furthermore, girls displayed a continuous decrease in enjoyment from sixth grade to eighth grade. Wallhead and Buckworth (2004) demonstrated significant positive relation between enjoying PE class and PA levels in girls. Thus PE teachers should urgently focus greater attention on the needs of this population and consider innovative and enjoyable school PE programs which include girls' popular digital world interests.

Video games attract the attention of children of almost all age groups all over the world. Video games are generally considered to be one of the main causes of physical inactivity, sedentary behavior and increased levels of obesity (Hill et al., 2003; Lam et al., 2011). But Exergame (EG), which is one of the new generation video game, is quite different from the sedentary style video games. Because EG requires physical movement (Vaghetti et al., 2018). It allows children to exercise while playing digital games. This device, which has a wide variety of game content from dance to team or individual sports, combines children's interest in games with exercise (Lam et al., 2011). Some studies have shown that using EG non-school intervention can improve body image (Chacon et al., 2016) psychological well-being (Staiano, Abraham, \& Calvert, 2012), self-efficacy (Finco et al., 2015a), self-esteem (Duman et al., 2016), and mood states (Andrade et al., 2019) in children and adolescents. Positive results from studies in recent years have drawn the attention of researchers to evaluate the impact of EG-based school-based PE programs. According to our previous systematic review (Birinci et al., 2020), EG can be an effective educational tool for motivating students to actively participate in PE. Many studies revealed that EG-based PE, was perceived as more fun and exciting for students than the traditional PE curriculum (Finco et al., 2015b; Robertson et al., 2016; Thembelihle, 2017). Similarly, Coknaz et al. (2019) demonstrated that 12 weeks of EG intervention had beneficial effects on fun, happiness, and excitement in tech-savvy inactive children.

In this regard, identifying the new methods of changing attitudes toward PE among girls early in the middle school years can help educators in their efforts to prevent the potential decline in PA among girls after school life. The purpose of this study was to evaluate the effects of dance-based exergaming implemented in a typical PE classroom on the attitude of female children students towards physical education. In line with previous research, we hypothesized that girls would show better PE attitudes after 8 weeks of dance-based EG intervention.

\section{Method}

\subsection{The Study Group}

The research sample consisted of 15 female secondary school (8th grade) students in the 2018-2019 academic year in public school (Yildırım Fatih Sultan Mehmet Secondary School) of Bursa. This research was carried out with the approval of the Bursa Provincial Directorate of National Education numbered 86896125-605.01-E.11114244 and conducted in accordance 
with the Declaration of Helsinki. Students were asked to participate on a voluntary basis. All participants' parents signed an informed form before the study.

\subsection{Procedure}

The participants performed all the practices in the classroom where converted into an exergame-lab. The laboratory consists of an area where 4 players can dance at the same time, a LED screen (Vestel, TUR) and a home video game console (Microsoft Xbox Kinect 360 with dance-based exergames (Just dance 2018, Ubisoft, UK). The participant was 1.5 to $2 \mathrm{~m}$ away from the Kinect sensor. Before initiation of each session, the position of the sensor was adjusted for the participants to ensure maximum motion capture and optimal position. Before the intervention, the participants were first given a demonstration of all games and were told about the procedures.

Then participants performed dance-based exergames for 80 minutes ( 3 sets of 20 minutes sessions, 10 minutes rest between sessions), 3 days a week for 8 weeks ( 24 sessions in total). Music and dance content were changed after each 20-minute game. A maximum of 4 students practiced in each session. By avoiding the repetition of the same game, the choice of games is entirely left to the participants. Participants answered the Physical Education and Sports Attitude Scale (PESAS) before the first exergame session and at the end of 8 weeks.

\subsection{Data Collection Tools}

\subsubsection{Demographics}

In this section, the participant's grade, sex, weight, height, weekly hours of video or mobile game playing, and whether or not students had a sport license (participated in sports) were recorded with the questionnaire prepared by the researchers.

Body mass index was determined using a Bioelectrical Impedance Analyzer (TANITA, TBF300 Japan). The heights of the subjects were measured using a meter while their bodies were in an upright position with an accuracy of $1 \mathrm{~mm}$.

\subsubsection{Physical Education and Sports Attitude Scale (PESAS)}

This questionnaire was adapted into Turkish by Demirhan and Altay (2001). The validated Turkish version of PESAS includes 24 items, with a 5-point Likert type response scale with anchors of 1: Strongly disagree and 5: Strongly agree. Twelve of 24 items are positive and 12 of them are negative. Total possible scores range from 24 to 120. Cronbach coeicient alpha reliability was .94 (Demirhan \& Altay, 2001).

\subsection{Data Analysis}

Statistical analysis was performed using the SPSS software version 20.0. Shapiro-Wilk and Kolmogorov-Smirnov tests were used to determine whether the variables are normally distributed. Mann-Whitney $U$ test was used for pairwise comparisons, Kruskal-Wallis Analysis of Variance was used for multiple comparisons. The relationships between the variables were examined with the Spearman-correlation coefficient. $\mathrm{p}<0.05$ was regarded as statistically significant. 


\section{Macrothink}

\section{Results}

\subsection{Demographic Characteristics of Participants}

Characteristics of the participants are shown in Table 1.

Table 1. Demographic characteristics of participants. Data presented as means $\pm \mathrm{SD}$

\begin{tabular}{|l|l|}
\hline Measures & $\mathbf{N}=\mathbf{1 2}$ \\
\hline Age (years) & $15.7 \pm 0.6$ \\
\hline Body Height $(\mathrm{cm})$ & $159.8 \pm 5.6$ \\
\hline Body Weight $(\mathrm{kg})$ & $52.6 \pm 4.1$ \\
\hline BMI $\left(\mathrm{kg} / \mathrm{m}^{2}\right)$ & $21.1 \pm 2.2$ \\
\hline Video game playing $(\mathrm{h} / \mathrm{w})$ & $2.4 \pm 1.6$ \\
\hline Mobil game playing $(\mathrm{h} / \mathrm{w})$ & $8.9 \pm 2.4$ \\
\hline
\end{tabular}

Note. BMI: Body mass index; $\mathrm{kg} / \mathrm{m}^{2}$ : kilogram(s) per square meter; $\mathrm{kg}$ : kilogramme; $\mathrm{cm}$ : centimeter; $\mathrm{h} / \mathrm{w}$ : hours/week.

\subsection{Physical Education and Sports Attitude Scale (PESAS) Scores}

Comparison of the participants' Physical Education and Sports Attitude Scale (PESAS) pre-test and post-test scores were given figure 1. A statistically significant difference was found between the participants' Physical Education and Sports Attitude Scale PESAS pre-test [78 (72-163)] and post-test [150 (123-171)] scores $(\mathrm{p}=0.001)$. 


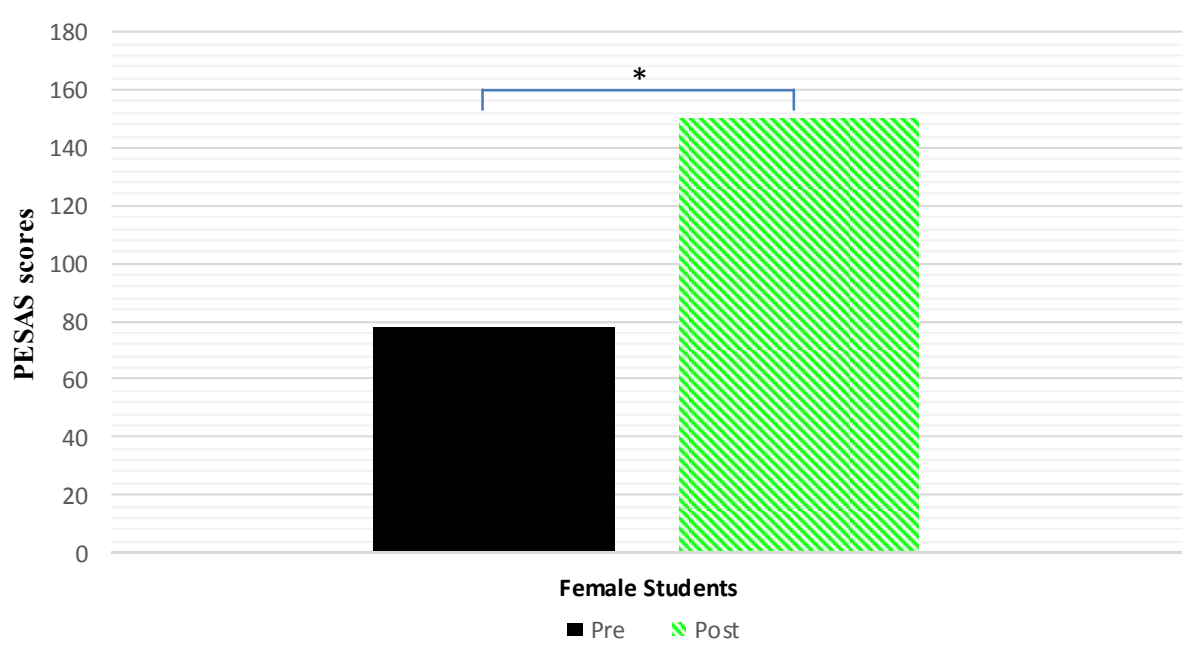

Figure 1. Comparison of the participants' Physical Education and Sports Attitude Scale (PESAS) pre-test and post-test scores

Note. ${ }^{*} \mathrm{p}<0.05$ indicates a significant difference.

\section{Discussion}

The present study investigated the effects of 8 weeks dance-based exergaming implemented in a typical PE classroom on the attitude of female children students towards PE. To the best our knowledge in the literature, there is no study to investigate the effect of EG on the attitudes towards physical education, especially in the female student population. The results of this study showed that 8 weeks [ 80 minutes ( 3 sets of 20 minutes sessions, 10 minutes rest between sessions), 3 days a week] exergame intervention had a significant positive impact on the attitude of inactive female children students towards PE. This supports our hypothesis that EG can have positive impact on PE attitudes after 8 weeks of dance-based EG intervention in 8 th-grade female students.

In line with our findings, Reategui et al. (2016) investigated whether EG could contribute to the development of positive student attitude toward PE. Participants (19 boys and 9 girls from 7 th grade of elementary school to the 3 rd grade of high school, mean age $=13$ years) attended an exergame lab (Your Shape Fitness, Kinect adventures and kinect sports) once a week, for a period of 20 weeks. According to results authors concluded that EG is a promising educational method in PE, contributing to the development of positive attitudes toward the PE. Glapa et al. (2018) showed that the efficacy of EG (Brain Breaks) incorporated PE in influencing drivers of PA in primary school children (170 boys and 156 girls, aged 9-11 years from 3rd to 5th grade). Finco et al. (2015a) investigated using EG in traditional PE with dissatisfaction and inactive students. Students $(n=24$, age $=8-14$-years $)$ that usually did not show interest in PE started to demonstrate a positive attitude after EG practices. Andrade et al. (2020) investigated the effect of exergames on the mood and self-esteem of children and compare that with traditional PE classes. 213 children (7-11 years old), from the fourth and fifth grades of elementary school (59 boys, 81 girls; mean age $9.41 \pm 0.48$ years), divided into 
an EG group $(n=68)$ and a PE group $(n=72)$. The EG group practiced dance-based exergames (XBOX: Just Dance 2015) during three 40-minute classes, and the PE group held three routine curricular PE classes. After the intervention EG group demonstrated reduced tension and vigor was higher in girls in the EG than in those in the PE group. We think that female students perceive EG intervention as interesting and fun. In addition, it is thought that physical activity is no longer tiring and boring for them. For this reason, it can be said that the attitudes of the students towards the physical education lesson may have changed in a positive way.

In addition, in terms of enriching the discussion, it has been taken into account in studies examining the effects of EG on attitudes towards PA. Because one of the most important goals of PE is to give students a positive attitude towards PA. Çoknaz et al. conducted a study examining the effects of 12 weeks (50-60 min, 3 days a week, 32 sessions in total) of EG (Nintendo Wii, many games under the title of sports, balance, aerobics, resort and training) play in inactive and technologically engaged children. Results showed that the enjoyment of the children in the exergame group was higher compared to the control group and motivated to continue to play games. Gao et al. (2013) examined the relationships between children's (112 boys and 113 girls elementary school students, age $=8$-14 years) situational motivation and PA levels in an EG (weekly 30-min for 18 weeks, Dance Dance Revolution) and perceived PA enjoyment. According to the authors, EG had a beneficial effect on intrinsic motivation to PA. Similarly Lee et al. (2016) investigated the acute effect of playing a single bout of EG (30-min, 12 EG station, e.g., Just Dance, Wii Fit, Wii Sports, and Wii Cardio Workout) on children's ( 3 rd and 4th-grade students, $n=134$, age $=8-11$ years) mood change and whether mood change differed by gender. Results demonstrated that EG significantly reduced anger and depression whereas no gender difference was revealed.

In our study, no control group was involved. And the use of only one school and a very small study population to conduct the study makes it difficult to generalize the results. In order to clear results of the effect of using exergame in PE, future studies should add more schools and participants. Only one data collection tool was used in this study. It is likely that the data acquired by more tools to be used in future studies will produce more reliable results. In addition, only a dance-based EG was conducted in this study. As a matter of fact, EG contain a wide variety. In this respect, further studies that will evaluate which games are more suitable for PE may be useful for the literature.

\section{Conclusion}

In conclusion, based on the results of the study, dance-based EG is useful educational tool for developing positive attitudes towards PE in female children students. Therefore, EG can consider as an educational tool to be introduced in PE curriculum, keeping in mind the childrens' growing interest in digital world. It is important to know that the use of the EG in PE should be deliberately planned to meet curriculum outcomes, taking into account a student-oriented learning environment. 


\section{Acknowledgements}

The authors would like to thank the participants, participants' parents, and Bursa Y1ldirım Fatih Sultan Mehmet Secondary School's principal. The authors have no conflict of interests to declare. The datasets generated during and/or analyzed during the current study are not publicly available but are available from Dr. Birinci who is the corresponding author for the study.

\section{References}

Andrade, A., Correia, C. K., Cruz, W. M. D., \& Bevilacqua, G. G. (2019). Acute effect of exergames on children's mood states during physical education classes. Games for Health Journal, 8(4), 250-256. https://doi.org/10.1089/g4h.2018.0083

Andrade, A., Cruz, W. M. D., Correia, C. K., Santos, A. L. G., \& Bevilacqua, G. G. (2020). Effect of practice exergames on the mood states and self-esteem of elementary school boys and girls during physical education classes: A cluster-randomized controlled natural experiment. PLoS ONE, 15(6), e0232392. https://doi.org/10.1371/journal.pone.0232392

Birinci, Y. Z., Korkmaz, N. H., \& Öztürk, İ. E. (2020). Can Exergames Use As an Educational Tool in Physical Education for Cognitive, Social, and Affective Domains? International Journal of Scientific and Technological Research, 6, 151-166. https://doi.org/ 10.7176/JSTR/6-06-11

Cairney, J., Kwan, M. Y., Velduizen, S., Hay, J., Bray, S. R., \& Faught, B. E. (2012). Gender, perceived competence and the enjoyment of physical education in children: A longitudinal examination. International Journal of Behavioral Nutrition and Physical Activity, 9(1), 1-8. https://doi.org/10.1186/1479-5868-9-26

Chacon, R., Zurita, F., Castro, M., Espejo, T., Martinez-Martinez, A., \& Linares, M. (2016). Research of the Applicability of Exergames for the Improvement of Obesity Index and Body Image in School Children. Revista Iberoamericana de Psicología del Ejercicio y el Deporte, 11(1), 97-105.

Coknaz, D., Mirzeoglu, A. D., Atasoy, H. I., Alkoy, S., Coknaz, H., \& Goral, K. (2019). A digital movement in the world of inactive children: favourable outcomes of playing active video games in a pilot randomized trial. European Journal of Pediatrics, 178(10), 1567-1576. https://doi.org/10.1007/s00431-019-03457-x

Demirhan, G., \& Altay, F. (2001). Lise birinci sınıf öğrencilerinin beden eğitimi ve spora ilişkin tutum ölçeği II. Spor Bilimleri Dergisi, 12(2), 9-20. https://doi.org/10.31680/ gaunjss.410742

Duman, F., Kokaçya, M. H., Doğru, E., Katayıfc1, N., Canbay, Ö., \& Aman, F. (2016). The role of active video-accompanied exercises in improvement of the obese state in children: A prospective study from Turkey. Journal of Clinical Research in Pediatric Endocrinology, 8(3), 334. https://doi.org/10.4274/jcrpe. 2284 


\section{Macrothink

Finco, M. D., Reategui, E. B., \& Zaro, M. A. (2015a). Exergames lab: A complementary space for physical education classes. Movimento, 21(3), 687-699. https://doi.org/10.22456/ 1982-8918.52435

Finco, M. D., Reategui, E., Zaro, M. A., Sheehan, D. D., \& Katz, L. (2015b). Exergaming as an alternative for students unmotivated to participate in regular physical education classes. International Journal of Game-Based Learning, 5(3), 1-10. https://doi.org/10.4018/IJGBL. 2015070101

Fogel, V. A., Miltenberger, R. G., Graves, R., \& Koehler, S. (2010). The effects of exergaming on physical activity among inactive children in a physical education classroom. Journal of Applied Behavior Analysis, 43(4), 591-600. https://doi.org/10.1901/jaba.2010. 43-591

Gao, Z., Podlog, L., \& Huang, C. (2013). Associations among children's situational motivation, physical activity participation, and enjoyment in an active dance video game. Journal of Sport and Health Science, 2(2), 122-128. https://doi.org/10.1016/j.jshs.2012. 07.001

Glapa, A., Grzesiak, J., Laudanska-Krzeminska, I., Chin, M. K., Edginton, C. R., Mok, M. M. C., \& Bronikowski, M. (2018). The impact of brain breaks classroom-based physical activities on attitudes toward physical activity in polish school children in third to fifth grade. International Journal of Environmental Research and Public Health, 15(2), 368. https://doi.org/10.3390/ijerph15020368

Hill, J. O., Wyatt, H. R., Reed, G. W., \& Peters, J. C. (2003). Obesity and the environment: Where do we go from here? Science, 299(5608), 853-855. https://doi.org/10.1126/science. 1079857

Jekauc, D. (2015). Enjoyment during exercise mediates the effects of an intervention on exercise adherence. Psychology, 6(01), 48. https://doi.org/10.4236/psych.2015.61005

Kooiman, B. J., \& Sheehan, D. P. (2015). The efficacy of exergames for social relatedness in online physical education. Cogent Education, 2(1), 1045808. https://doi.org/10.1080/ 2331186X.2015.1045808

Korkmaz, N. H., Birinci, Y. Z., Öztürk, İ. E., \& Uğur, S. (2020). Beden Eğitimi Ve Spor Derslerinde Exergames: Çocuklar Üzerine Fiziksel Etkileri. Social Sciences Studies Journal, 74, 5157-5175. https://doi.org/10.26449/sssj.2791

Lam, J. W., Sit, C. H., \& McManus, A. M. (2011). Play pattern of seated video game and active "exergame" alternatives. Journal of Exercise Science \& Fitness, 9(1), 24-30. https://doi.org/10.1016/S1728-869X(11)60003-8

Lee, J. E., Xiang, P., \& Gao, Z. (2017). Acute effect of active video games on older children's mood change. Computers in Human Behavior, 70, 97-103. https://doi.org/ 10.1016/j.chb.2016.12.060 


\section{Macrothink

Reategui, E., Bittencourt, M. Z., \& Mossmann, J. B. (2016). Students' Attitudes in Relation to Exergame Practices in Physical Education (pp. 1-4). 8th International Conference on Games and Virtual Worlds for Serious Applications. https://doi.org/10.1109/VS-GAMES.2016. 7590369

Robertson, J., Jepson, R., Macvean, A., \& Gray, S. (2016). Understanding the importance of context: A qualitative study of a location-based exergame to enhance school childrens physical activity. PLoS ONE, 11(8), e0160927. https://doi.org/10.1371/journal.pone.0160927

Schneider, M. L., \& Kwan, B. M. (2013). Psychological need satisfaction, intrinsic motivation and affective response to exercise in adolescents. Psychology of Sport and Exercise, 14(5), 776-785. https://doi.org/10.1016/j.psychsport.2013.04.005

Staiano, A. E., Abraham, A. A., \& Calvert, S. L. (2012). Motivating effects of cooperative exergame play for overweight and obese adolescents. Journal of Diabetes Science and Technology, 6, 812-819. https://doi.org/10.1177/193229681200600412

Thembelihle, G. (2017). Exploring Use of Exergames in Physical Education Classes as a Way to Curb Obesity and Promote Health in Children and Adolescents in Zimbabwe. European Journal of Physical Education and Sport Science, 3(6), 122-131. https://doi.org/ 10.5281/zenodo.815639

Treanor, L., Graber, K., Housner, L., \& Wiegand, R. (1998). Middle school students' perceptions of coeducational and same-sex physical education classes. Journal of Teaching in Physical Education, 18(1), 43-56. https://doi.org/10.1123/jtpe.18.1.43

Vaghetti, C. A. O., Monteiro Junior, R. S., Finco, M. D., Reategui, E. B., \& Botelho, S. S. D. C. (2018). Exergames experience in physical education: A review. Physical Culture and Sport. Studies and Research, 78, 23-32. https://doi.org/10.2478/pcssr-2018-0010

Wallhead, T. L., \& Buckworth, J. (2004). The role of physical education in the promotion of youth physical activity. Quest, 56(3), 285-301. https://doi.org/10.1080/00336297.2004. 10491827

\section{Copyright Disclaimer}

Copyright for this article is retained by the author(s), with first publication rights granted to the journal.

This is an open-access article distributed under the terms and conditions of the Creative Commons Attribution license (http://creativecommons.org/licenses/by/3.0/). 